\title{
ANALISIS DISTRIBUSI TEMPERATUR MEDIA PENAMPUNG BAHAN BAKAR BEKAS REAKTOR DAYA EKSPERIMENTAL (RDE) MENGGUNAKAN FLUENT 6.3
}

\author{
Balya Lutviana Laila Saro ${ }^{1, \mathrm{a}}$, Fiber Monado ${ }^{1, \mathrm{~b}}$, Muhammad Subekti ${ }^{2, \mathrm{c}}$ \\ ${ }^{1}$ Jurusan Fisika, Fakultas Matematika dan Ilmu Pengetahuan Alam-Universitas Sriwijaya \\ ${ }^{2}$ Pusat Teknologi Reaktor dan Keselamatan Nuklir-BATAN
}

\begin{abstract}
ABSTRAK
ANALISIS DISTRIBUSI TEMPERATUR MEDIA PENAMPUNG BAHAN BAKAR BEKAS REAKTOR DAYA EKSPERIMENTAL (RDE) MENGGUNAKAN FLUENT 6.3. Konsep dan desain reaktor daya eksperimental (RDE) adalah mengacu pada HTGR (High Temperature Gas-cooled Reactor) dari teknologi Jerman yang telah diterapkan pada HTR-10 di Cina yang dirancang menggunakan bahan bakar yang berbentuk pebble bed. Setelah bahan bakar nuklir dimanfaatkan dalam reaktor nuklir, bahan bakar bekas tersebut kemudian akan masuk ke dalam tempat penampungan sementara. Penelitian ini dikhususkan pada aspek temohidrolik karena peranannya yang sangat penting untuk menjamin keselamatan media penampung bahan bakar bekas Reaktor Daya Eksperimental (RDE). Oleh karena itu diperlukan alat bantu berupa progam (software) komputer dalam proses penganalisaan distribusi temperatur media penampung bahan bakar bekas Reaktor Daya Eksperimental (RDE). Program yang digunakan adalah FLUENT 6.3. Hasil perhitungan menunjukan bahwa terjadi penurunaan temperatur secara bertahap pada bahan bakar bekas di setiap posisinya, dari titik pusat di posisi $0 \mathrm{~m}$ sebesar $110^{\circ} \mathrm{C}$ ke dinding media penampung di posisi $0,3 \mathrm{~m}$ sebesar $30^{\circ} \mathrm{C}$. Sehingga dari hasil tersebut distribusi temperatur media penampung bahan bakar bekas reaktor daya eksperimental dapat dianggap aman tanpa kerusakan akibat dari panas.
\end{abstract}

Kata kunci: distribusi temperatur, media penampung, bahan bakar bekas, Reaktor Daya Eksperimental (RDE), FLUENT 6.3.

\section{ABSTRACT}

ANALYSIS OF TEMPERATURE DISTRIBUTION FOR THE SPENT FUEL STORAGE MEDIA EXPERIMENTAL POWER REACTOR (EPR) USING FLUENT 6.3. The concept and design of the experimental power reactor (RDE) refers to the HTGR (High Temperature Gas-cooled Reactor) of German technology that has been applied to HTR-10 in China designed using pabble bed fuel. After nuclear fuel is used in nuclear reactors, spent fuel will enter temporary shelters. This research is devoted to the thermal hydraulics aspects because its role is very important to ensure the safety of the spent fuel storage media experimental power reactor (EPR). Therefore, it is necessary to use computer software program aids in the process of analyzing the temperature distribution for the spent fuel storage media experimental power reactor (EPR). The programs that used is FLUENT 6.3. The calculation results show that there is a gradual decrease in the spent fuel temperature in each position, from the center point at position $0 \mathrm{~m}$ by $110^{\circ} \mathrm{C}$ to the media wall of the storage in the position of $0.3 \mathrm{~m}$ by $30^{\circ} \mathrm{C}$. So from that data storage media can be considered safe from the heat of spent fuel.

Keywords: temperature distribution, storage media, spent fuel, Experimental Power Reactor (EPR), FLUENT 6.3 


\section{PENDAHULUAN}

Reaktor Daya Eksperimental (RDE) merupakan reaktor nuklir yang dapat digunakan untuk pembangkit listrik, pembangkit panas dan untuk memproduksi hidrogen. Karena sifatnya yang eksperimental maka pengoperasian reaktor nuklir tersebut lebih banyak untuk tujuan percobaan dalam meningkatkan penguasaan teknologi. Selain itu Reaktor Daya Ekperimental (RDE) merupakan salah satu jenis reaktor temperatur tinggi berpendingin gas helium yang segera akan dibangun di Indonesia oleh BATAN di Kawasan PUSPIPTEK Serpong. Konsep dan desain Reaktor Daya Eksperimental (RDE) mengacu pada HTGR (High Temperature Gas-cooled Reactor) dari teknologi Jerman yang telah diterapkan pada HTR-10 di Cina. Reaktor Daya Eksperimental (RDE) dirancang menggunakan bahan bakar yang berbentuk pebble bed [1].

Setelah bahan bakar nuklir dimanfaatkan dalam reaktor nuklir dan mencapai derajat bakar tertentu, elemen bakar nuklir akan menjadi sangat radioaktif karena mengandung unsur-unsur radioakif beraktivitas sangat tinggi hasil proses fisi. Bahan bakar bekas tersebut kemudian akan masuk ke dalam tempat penampungan sementara agar unsur-unsur hasil fisi yang radioaktif itu meluruh sehingga radiasi yang dipancarkannya menjadi rendah. Dalam tempat penampungan tersebut diharapkan bahan bakar bekas yang masih panas dapat didinginkan [2].

Dalam mendesain atau memodifikasi media penampung harus memperhatikan beberapa aspek keselamatan, antara lain aspek neutronik, aspek termohidrolik dan juga aspek radiologi. Untuk aspek neutronik desain media penampung harus memastikan bahan bakar nuklir bekas yang disimpan di dalam media penampung tersebut dalam kondisi subkritis. Sedangkan untuk aspek termohidrolik desain dari media penampung harus bisa memindahkan panas yang berasal dari bahan bakar nuklir bekas. Sedangkan untuk aspek radiologi, desain dari media penampung harus mampu menjaga paparan di sekitar media penampung dibawah ambang batas paparan radiasi yang ditentukan oleh badan pengawas [3].

Penelitian ini dikhususkan pada aspek temohidrolik karena peranannya yang sangat penting untuk menjamin keselamatan media penampung bahan bakar bekas Reaktor Daya Eksperimental (RDE). Oleh karena itu diperlukan alat bantu berupa progam (software) komputer dalam proses penganalisaan distribusi temperatur media penampung bahan bakar bekas Reaktor Daya Eksperimental (RDE). Program yang digunakan adalah FLUENT 6.3, karena program ini merupakan program CFD (Computational Fluid Dynamic) yang sangat handal dalam perhitungan numerik untuk perpindahan panas yang melibatkan fluida 
dan juga lebih fleksibel untuk melakukan simulasi berbagai bentuk model [3].

Asumsi-asumsi yang akan dipakai dalam penelitian ini adalah sebagai berikut:

1. Jumlah bahan bakar bekas yang disimpan dalam media penampung $\leq$ 2000 pabbel bed.

2. Tidak ada kebocoran di dalam media penampung bahan bakar bekas.

3. Aliran yang ada di media penampung bahan bakar bekas adalah aliran laminar.

4. Fluks panas setiap bahan bakar bekas sebesar $1,05 \mathrm{w} / \mathrm{m}^{2}$ dan terjadi secara merata pada bagian bahan bakar bekas tersebut.

5. Perpindahan panas yang terjadi di media penampung bahan bakar bekas adalah konveksi alamiah.

Tujuan penelitian ini adalah untuk menganalisis distribusi temperatur media penampung bahan bakar bekas Reaktor Daya Eksperimental (RDE) menggunakan FLUENT 6.3.

\section{TEORI}

\section{Perpindahan Panas}

Perpindahan panas dapat di definisikan sebagai berpindahnya energi dari satu daerah ke daerah lainnya sebagai akibat dari beda suhu antara daerah-daerah tersebut dari temperatur fluida yang lebih tinggi ke fluida lain yang memiliki temperatur lebih rendah[4].

\section{Konduksi}

Konduksi adalah proses dimana panas mengalir dari daerah yang bersuhu tinggi kedaerah yang bersuhu lebih rendah di dalam satu medium (padat, cair atau gas) atau antara medium-medium yang berlainan yang bersinggungan secara langsung [5].

Persamaan dasar untuk konduksi satu dimensi dalam dapat ditulis ${ }^{[6]}$ :

$$
q_{k}=-k A \frac{\Delta T}{x}
$$

Dengan $q_{k}$ adalah laju perpindahan panas dengan cara konduksi (Watt), $A$ adalah luas permukaan $\left(\mathrm{m}^{2}\right), \Delta T$ adalah gradien suhu pada penampang $(\mathrm{K}), x$ adalah jarak dalam arah aliran panas (m), dan $k$ adalah konduktivitas termal bahan (W/m.K).

\section{Konveksi}

Konveksi adalah proses transport energi dengan kerja gabungan dari konduksi panas, penyimpanan dan gerakan mencampur. Konveksi sangat penting sebagai mekanisme perpindahan energi antara permukaan benda padat dan cairan atau gas [7].

Laju perpindahan panas dengan cara konveksi antara suatu permukaan dan suatu fluida dapat dihitung dengan hubungan [6]:

$$
q=h A\left(T_{w}-T_{f}\right)
$$

Dengan adalah $q$ laju perpindahan panas dengan cara konveksi (Watt), $A$ adalah luas penampang $\left(\mathrm{m}^{2}\right), T_{w}$ adalah temperatur dinding $(\mathrm{K}), T_{f}$ adalah temperatur fluida $(\mathrm{K})$, 
$h$ adalah koefisien perpindahan panas konveksi $\left(\mathrm{W} / \mathrm{m}^{2} . \mathrm{K}\right)$

Koefisien perpindahan panas konveksi $h$ bervariasi terhadap jenis aliran (aliran laminer atau turbulen), sifat-sifat fisik fluida, temperatur rata-rata, juga dipengaruhi oleh mekanisme perpindahan panas konveksi [8]

Perpindahan panas konveksi diklasifikasikan dalam konveksi bebas (free convection) dan konveksi paksa (forced convection) menurut cara menggerakkan alirannya [9].

\section{Radiasi}

Radiasi adalah proses dengan mana panas mengalir dari benda yang bersuhu tinggi ke benda yang bersuhu rendah bila benda-benda itu terpisah di lama ruang, bahkan bila terdapat ruang hampa di antara benda-benda tersebut. Semua benda memancarkan panas radiasi secara terusmenerus [6].

$$
q_{r}=e A \sigma\left(T_{1}^{4}-T_{2}^{4}\right)
$$

Dengan $q_{r}$ adalah laju perpindahan panas dengan cara radiasi (Watt), $e$ adalah emitasi permukaan benda hitam, $A$ adalah luas permukaan $\left(\mathrm{m}^{2}\right), \quad \sigma$ adalah konstanta dimensional $\left(0,174^{8} \mathrm{Btu} h f \mathrm{t}^{2}{ }^{\circ} \mathrm{C}\right), T_{1}$ adalah temperatur benda hitam $(\mathrm{K})$, dan $T_{2}$ adalah temperatur benda hitam yang mengelilinginya $(\mathrm{K})$.

\section{Computational Fluid Dynamics (CFD)}

\section{Computational Fluid Dynamics}

(CFD) adalah suatu analisa sistem yang melibatkan aliran fluida, perpindahan kalor dan fenomena-fenomena yang terkait di dalamnya seperti rekasi kimia yang dilakukan dengan simulasi berbasis komputer [10].

Pada umumnya terdapat tiga tahapan yang harus dilakukan saat simulasi CFD.

\section{Preprocessing}

Merupakan langkah pertama dalam membangun dan menganalisis sebuah model CFD. Teknisnya adalah membuat model benda kerja, membuat mesh, kemudian menerapkan kondisi batas dan sifat-sifat fluidanya.

\section{Solving}

Merupakan langkah untuk menghitung kondisi-kondisi yang diterapkan pada saat preprocessing.

\section{Postprocessing}

Merupakan langkah terakhir dalam analisis CFD. Hal yang dilakukan pada langkah ini adalah mengorganinasi dan menginterpretasi data hasil simulasi CFD berupa gambar, kurva dan animasi [11]. 


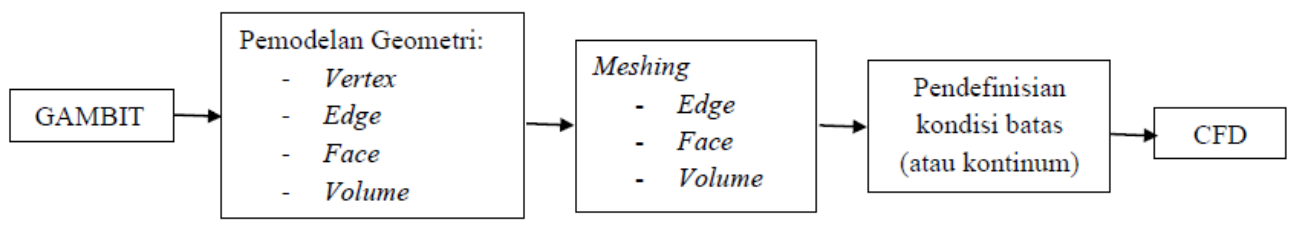

Gambar 1. Proses GAMBIT - CFD[12]

\section{FLUENT}

FLUENT merupakan program yang digunakan untuk mensimulasikan perpindahan kalor dan aliran fluida dengan berbagai bentuk geometri. Permasalahan diselesaikan dengan menggunakan bantuan mesh, dimana mesh yang didukung oleh FLUENT adalah 2D triangularquadrilateral, 3D tetrahedral - hexahedralpyramid-wedge, dan mesh campuran. Langkah-langkah penyelesaian masalah menggunakan Fluent adalah sebagai berikut:

1. Membuat geometri dan mesh pada model.

2. Memilih model yang tepat (2D atau 3D).

3. Mengimpor mesh model.

4. Melakukan pemeriksaan pada mesh model.

5. Memilih model yang sesuai dengan permasalahan seperti fomulasi solver, energi, viskositas, dan lain-lain.

6. Menentukan sifat material yang terdapat dalam permasalahan.

7. Menentukan kondisi batas.

8. Mengatur parameter kontrol solusi.

9. Melakukan initialize.

10. Melakukan iterasi.
11. Hasil iterasi dapat ditampilkan dalam bentuk kontur, vektor, pathline, dan lain-lain [13].

\section{METODE PENELITIAN}

\section{Melakukan Pemodelan}

Langkah pertama dalam melakukan analisis distribusi temperatur media penampung bahan bakar bekas Reaktor Daya Eksperimental (RDE) adalah melakukan metode pemodelan. Pemodelan dilakukan dengan bantuan software GAMBIT 2.3 (Geometry and Mesh Building Intelligent Toolkit). Model media penampung bahan bakar bekas Reaktor Daya Eksperimental (RDE) didesain seperti tangki penyimpanan bahan bakar bekas yang telah diterapkan pada HTR-10 di Cina, dengan lapisan laras stainless steel kemudian di isi $\leq 2000$ bahan bakar bekas berbentuk pebble bed dengan bahan material grafit. Desain model media penampung bahan bakar bekas Reaktor Daya Eksperimental (RDE) dapat digambarkan seperti pada gambar di bawah ini: 


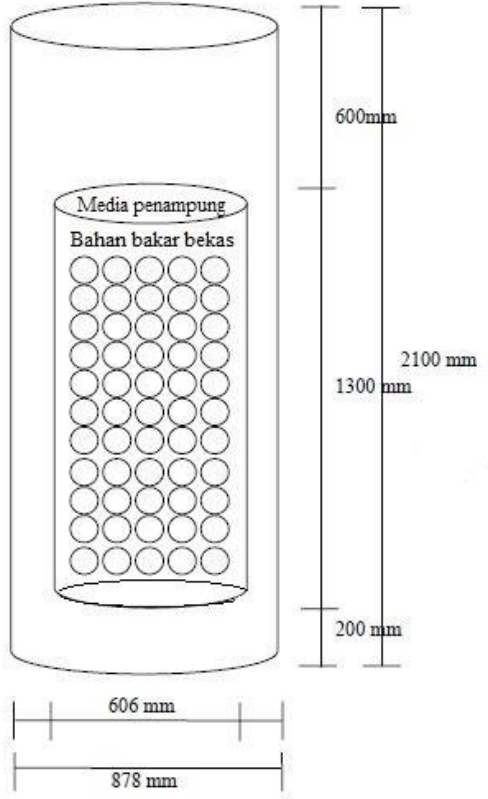

Gambar 2. Model media penampung bahan bakar bekas reaktor daya eksperimental

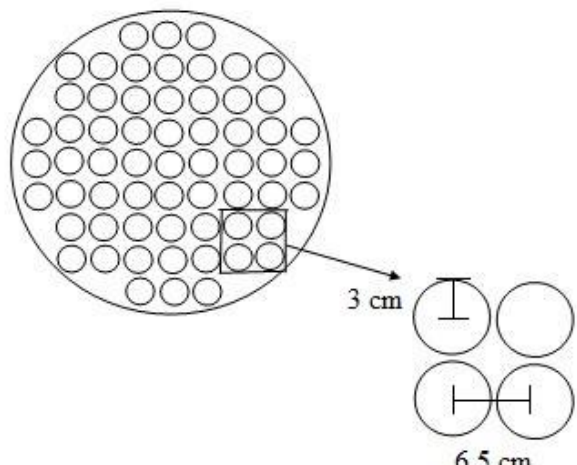

Gambar 3. Susunan bahan bakar bekas di dalam media penampung

Penyederhanaan dilakukan dengan adanya faktor simetri daripada susunan bahan bakar bekas yang dikaji. Selanjutnya pembuatan model media penampung hanya mencakup seperdelapan (1/8) dari susunan bahan bakar bekas di dalam media penampung seperti yang ditunjukan dalam Gambar 3.

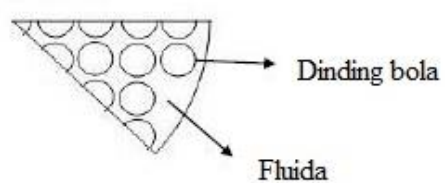

(a)

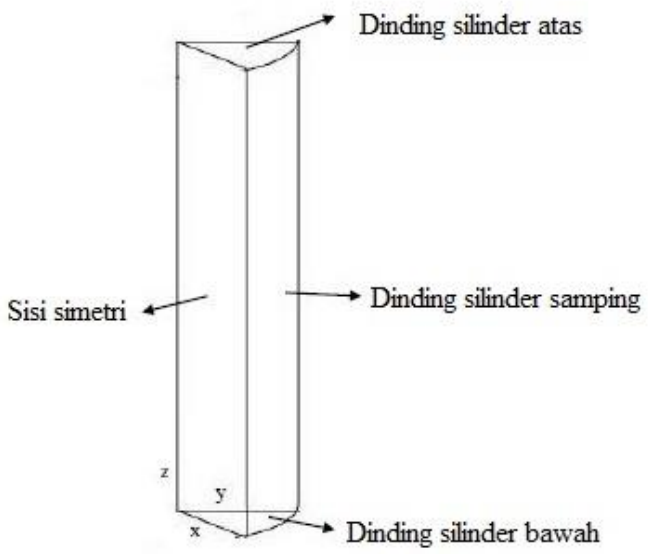

(b)

Gambar 4. Geometri 1/8 pada media penampung bahan bakar bekas reaktor daya eksperimental (a) Tampak dari atas dan (b) Tampilan geometri model 3 dimensi.

\section{Metode Simulasi}

Langkah selanjutnya adalah melakukan simulasi terhadap model media penampung bahan bakar bekas Reaktor Daya Eksperimental (RDE). Tujuannya untuk menganalisis distribusi temperatur media penampung bahan bakar bekas Reaktor Daya Eksperimental (RDE) dengan menggunakan software analisis komputasi fluida dinamik (Computational Fluid Dynamics/CFD) FLUENT 6.3.

\section{Diagram Alir}

Langkah-langkah yang dilakukan untuk melakukan pemodelan dan simulasi dengan software GAMBIT 2.3 dan FLUENT 6.3 dapat dilihat pada Gambar 5. 


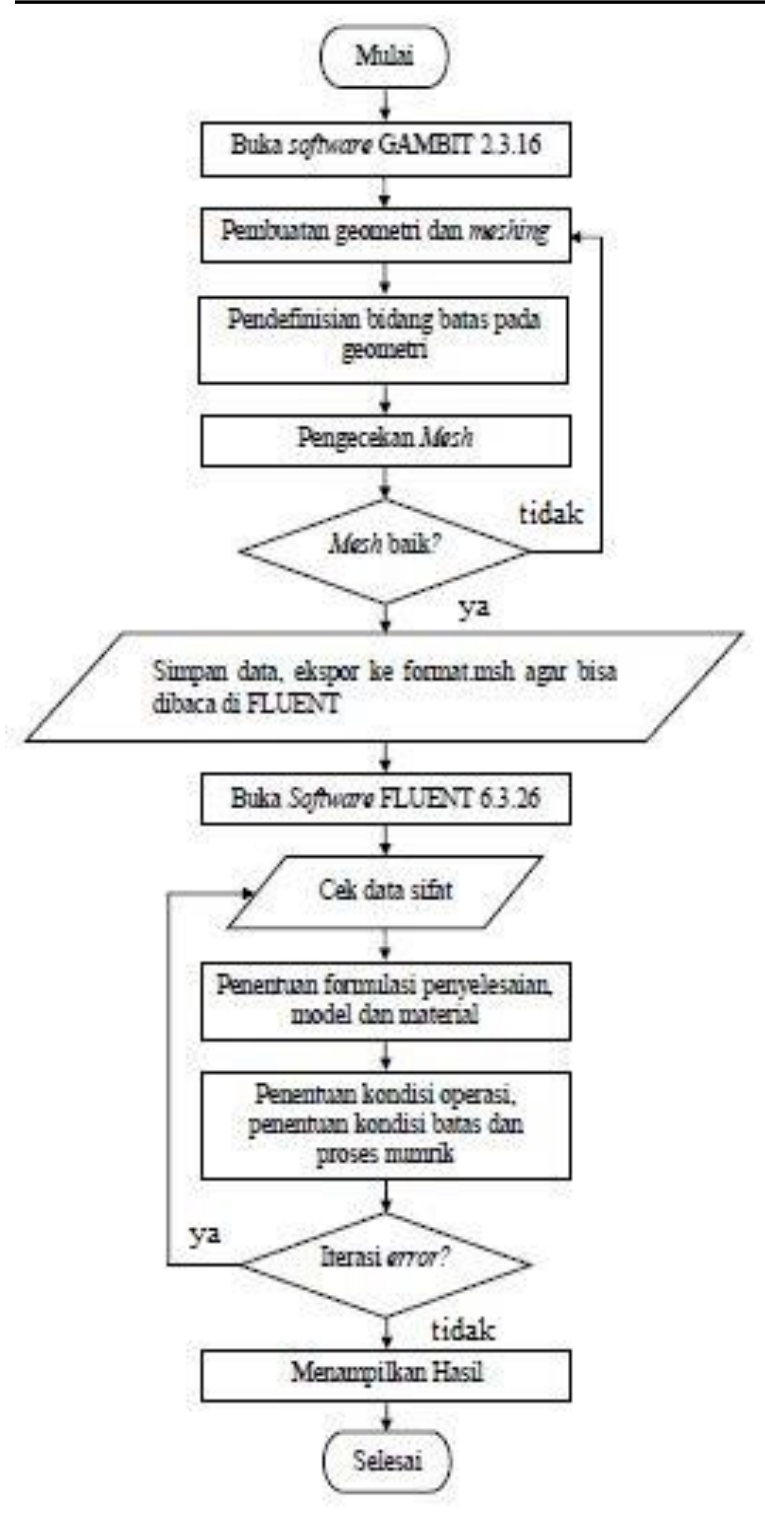

Gambar 5. Diagram alir pemodelan dan simulasi distribusi temperatur media penampung bahan bakar bekas Reaktor Daya Eksperimen pada GAMBIT 2.3 dan FUENT6.3

\section{HASIL DAN PEMBAHASAN}

Simulasi dengan program FLUENT 6.3 ini diawali dengan langkah iterasi dengan indikasi terdapat pernyataan konvergensi dari grafik seperti yang ditampilkan pada Gambar 6. Grafik tersebut berupa jumlah iterasi pada sumbu $\mathrm{x}$ dan convergent criteria pada sumbu y yang menyatakan batasan residual tersebut konvergen. Dari grafik iterasi numerik menunjukkan bahwa program FLUENT 6.3 dapat bekerja secara benar dengan indikasi residual errornya semakin kecil.

Hasil proses perhitungan menggunakan FLUENT 6.3 menunjukan tampilan 3D dari pemodelan geometri 1/8 pada media penampung bahan bakar bekas Reaktor Daya Eksperimental, dengan hasil keluaran berupa kontur dan grafik. Media penampung tersebut memiliki ukuran dengan radius $0,3 \mathrm{~m}$ dan tinggi $1,3 \mathrm{~m}$ seperti yang ditampilkan pada Gambar 7 . Dari gambar tersebut memperlihatkan besarnya suhu dilukiskan dari harga yang paling tinggi berwarna merah 

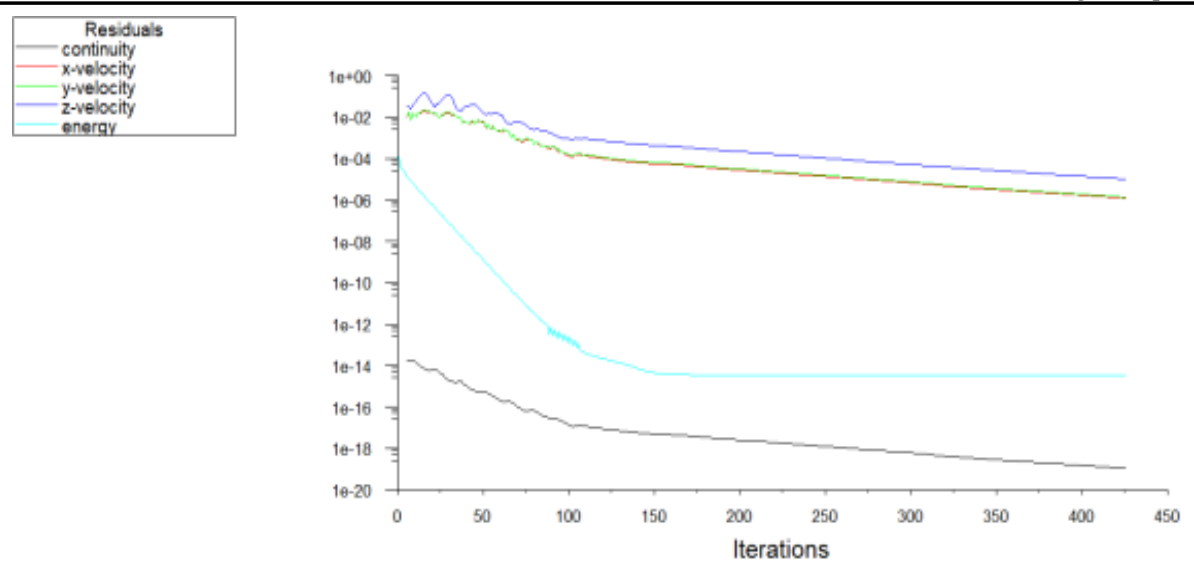

Gambar 6. Skala residual
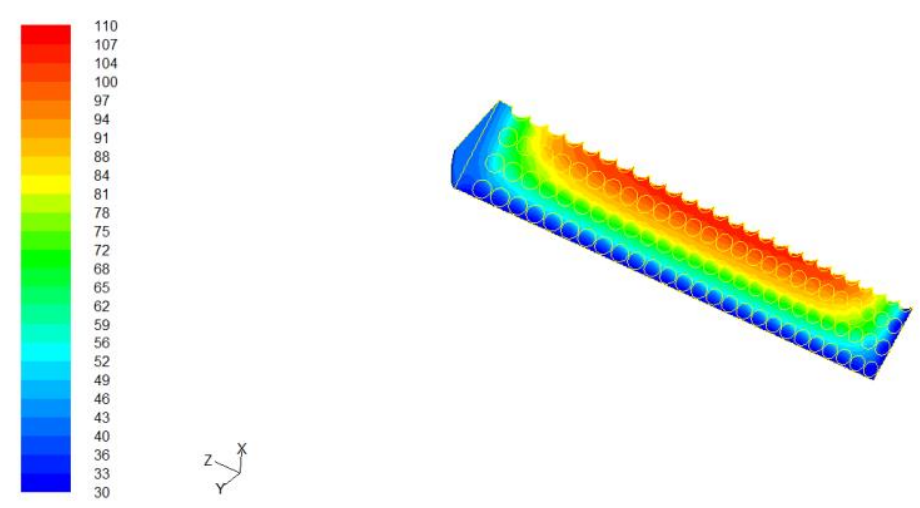

Contours of Total Temperature (c) (Time $=0.0000 e+00)$ FLUENT 6.3 (3d, dp, pbns, Jam, unst. 2015

Gambar 7. Distribusi temperatur media penampung bahan bakar bekas RDE

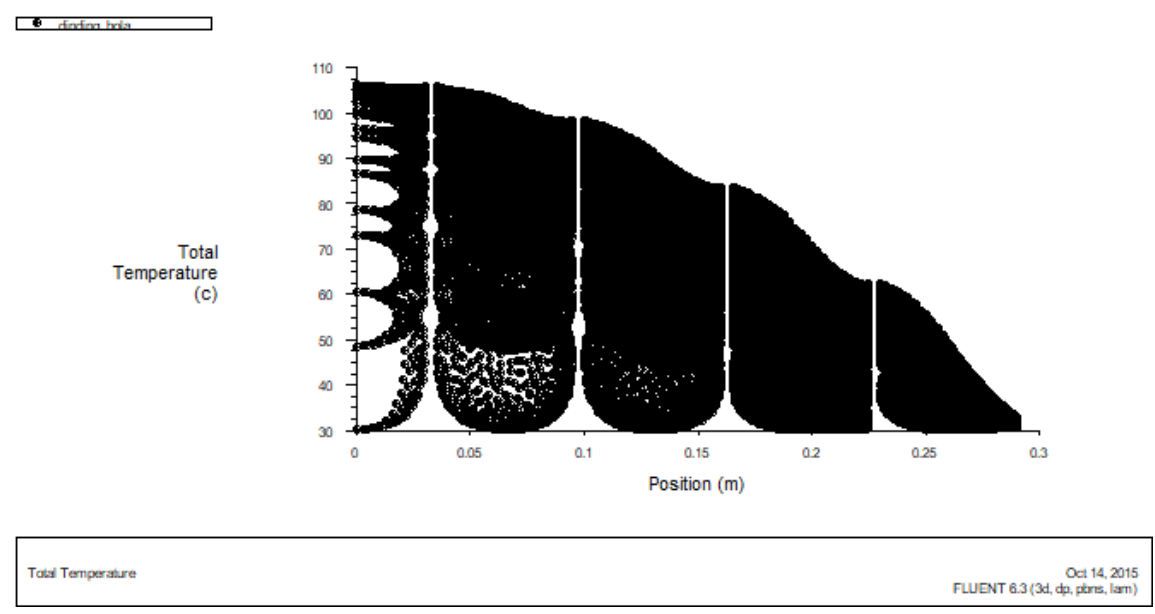

Gambar 8. Hubungan antara posisi bahan bakar bekas terhadap temperatur

kemudian kuning, hijau dan yang kesesuaian dengan teori perpindahan panas terendah biru. Hal ini menunjukkan dapat terjadi karena adanya aliran 
percampuran dari bagian panas ke bagian yang dingin.

Pada Gambar 8. dapat dilihat adanya degradasi atau penurunan temperatur secara bertahap pada bahan bakar bekas di setiap posisinya. Bahan bakar bekas yang berada di titik pusat mempunyai temperatur yang lebih tinggi dibanding dengan bahan bakar bekas yang berada di pinggir dekat dengan dinding media penampung. Pada titik pusat di posisi $0 \mathrm{~m}$ bahan bakar bekas memiliki nilai temperatur maksimum sebesar $110^{\circ} \mathrm{C}$ sedangkan pada dinding media penampung di posisi $0,3 \mathrm{~m}$ bahan bakar bekas memiliki nilai temperatur minimum sebesar $30^{\circ} \mathrm{C}$. Sehingga dari data tersebut distribusi temperatur media penampung bahan bakar bekas reaktor daya eksperimental dapat dianggap aman tanpa ada kerusakan akibat dari panas.

\section{KESIMPULAN}

Hasil perhitungan menunjukan bahwa terjadi penurunaan temperatur secara bertahap pada bahan bakar bekas di setiap posisinya dari titik pusat ke dinding media penampung. Pada titik pusat di posisi $0 \mathrm{~m}$ bahan bakar bekas memiliki nilai temperatur maksimum sebesar $110^{\circ} \mathrm{C}$ sedangkan pada dinding media penampung di posisi $0,3 \mathrm{~m}$ bahan bakar bekas memiliki nilai temperatur minimum sebesar $30^{\circ} \mathrm{C}$. Sehingga dari data tersebut distribusi temperatur media penampung bahan bakar bekas reaktor daya eksperimental dapat dianggap aman tanpa ada kerusakan akibat dari panas.

\section{UCAPAN TERIMAKASIH}

Penulis mengucapkan terima kasih kepada Dr. R. Muhammad Subekti, S.T., M.Eng., Dr. Fiber Monado, S.Si., M.Si., Dr. Menik Ariani, S.Si., M.Si. dan Drs. Tukiran Surbakti atas saran dan perbaikan, sehingga makalah ini dapat ditulis dengan baik.

\section{DAFTAR PUSTAKA}

[1] SUWOTO, HERY ADRIAL, TOPAN SETIADIPURA, ZUHAIR. Analisis Perhitungan Distribusi Temperatur Teras dan Reflektor Reaktor Daya Eksperimental. Sigma Epsilon. 2016; 20; $2: 64-72$.

[2] A.HADIWINATA, A.WIDIHARTO, SIHANA. Desain Konsep Tangki Penampung Bahan Bakar Passive Compact Molten Salt Reactor. J. Tek. Reaktor. Nukl. 2011; 13; 2: 133-145.

[3] KHAKIM, A. Analisis Keselamatan Termohidrolik Bulk Shielding Reaktor Kartini. J. Tek. Reaktor. Nukl. 2015; 17; 3: 115-126.

[4] YUNUS, A.D. Perpindahan Panas dan Massa, Jakarta, Universitas Darma Persada; 2009.

[5] AMBARITA, H. Perpindahan Panas Konduksi dan Penyelesaian Analitik dan Numerik. Medan, Departemen Teknik Mesin FT USU; 2012. 
[6] INCROPERARA, F.P. AND DEWITT, D.P. Fundamental of Heat and Mass Transfer, Third Edition, Singapore, John Wiley \& Sons; 1982.

[7] AMBARITA, H. Perpindahan Panas Konveksi dan Pengantar Alat Penukar Kalor. Medan, Departemen Teknik Mesin FT USU; 2011.

[8] STOECKER, W.F. AND JONES, J.W. Refrigeration and Air Conditioning, New York, McGraw-Hill; 1982.

[9] HOLMAN, J.P. DAN JASJFI, E. Perpindahan Kalor, Jakarta, Erlangga; 2002.

[10] VERSTEEG, H.K. AND MALALASEKERA, W. An Introduction to Computational Fluid Dynamics The Finite Volume Method,
Malaysia, Longman Sc and Technical; 1995.

[11] TUAKIA, F. Dasar-dasar CFD Menggunakan FLUENT, Bandung, Informatika; 2008.

[12] FLUENT INC., GAMBIT 2.3 User's Guide, Lebanon, New Hampshire (USA); 2006.

[13] FLUENT INC. FLUENT 6.3 User's Guide, Lebanon, New Hampshire (USA); 2006. 